\section{ONE LASER, NUMEROUS APPLICATIONS}

Practices can use the SiroLaser Advance from Sident Dental Systems to whiten patients' teeth using its bleaching applications. They can also use it to enhance aesthetic results by improving impression-taking procedures through facilitating quicker exposure of crown margins and eliminating bleeding due to its strong haemostatic effect; creating more predictable results and reducing the number of post-operative complaints.

SIROLaser Advance can be used for soft tissue surgery in a variety of cosmetic dentistry applications as well as for disinfection in endodontic treatment, crown lengthening, treating periodontal pockets, and resolving peri-implantitis. In surgical applications it offers high precision tissue removal with minimal trauma to surrounding tissues, minimised bleeding for clearer visibility, protection against postoperative infection, minimised scar formation, an enhanced healing response and virtually no post-operative pain.

The easy-to-use touch screen menu makes it is very simple to set the treatment parameters because the most frequently used clinical applications have already been preset. To activate the SIROLaser Advance the operator can either use the wireless foot control or the finger switch on the hand piece.

For further information call Sident Dental Systems on 01932 582900 or email info@sident. co.uk.

\section{MOUTHWASH FOR PEACEFUL SLEEP}

Helps Stop Snoring throat rinse has a natural essential oils formula designed to help reduce snoring in users. The essential oils help tone the soft tissue at the back of the throat, which relaxes and vibrates during sleep and causes many to snore.

Gargling the mouthwash helps effectively deliver the formula to where it is needed most, and has added anti-bacterial and breath freshening benefits. Helps Stop Snoring throat rinse comes in a $250 \mathrm{ml}$ bottle, enough for 25 peaceful nights of sleep, and is used like any mouthwash after brushing teeth in the evening. www.stopsnoring. co.uk

\section{AVOID SIMPLE LEGAL PITFALLS}

Goodman Legal has earned a reputation as one of the most experienced law firms for dentists in the UK. It offers tailor made, reliable and practical guidance spanning a wide variety of legal issues. These range from the business side of practice, such as expense share and associate agreements, to the job itself, in areas concerning contracts and regulatory issues.

Effective legal advice can help practices avoid simple legal pitfalls that dentists can face in their day-to-day activities. For example, if you are considering the purchase of a dental practice or formation of a partnership agreement, advice from Goodman Legal can provide safeguards for your business.

Ray Goodman and his highly experienced team of lawyers have outstanding knowledge of current legal advice and guidelines. They work closely with PCTs to provide you with efficient and cost effective services.

For more information call 0151707 0090, email rng@ goodmanlegal.co.uk or visit www.goodmanlegal.co.uk.

\section{DENTAL SUPPLIERS JOIN FORCES}

Claudius Ash, supplying the dental industry since 1829 , have been fully integrated into the Plandent family.

The Finnish company Plandent was founded in 1972 and since then has grown to become one of the largest dental supply houses in Europe. Operating in over 15 countries and consolidating its buying operations, Plandent negotiates with manufacturers to ensure the most competitive prices for customers. Plandent's Orbis own label products include a range of competitively priced, quality sundry items.

The experienced equipment team at Plandent offer in-depth knowledge, dedicated after sales care and very competitive pricing as a direct result of the ex-factory distribution service.

Moving forward, Plandent has launched an intuitive inventory management system with Plan 0, an automated computerised system which will safeguard your consumables, ensuring that you never run out of stock whilst maintaining optimum levels for your individual practice.

For further information call Plandent on 0500500322.

\section{QUICK, EASY, PAINLESS ANAESTHESIA}

The Quicksleeper S4 delivers profound anaesthesia quickly, easily, painlessly and with no 'thick lips'.

Quicksleeper S4 enables dental professionals to perform osteocentral anaesthesia whereby a small amount of conventional local anaesthetic is placed in the spongy bone in between teeth. It delivers a profound anaesthesia almost instantaneously, particularly useful for treating children and other potentially nervous patients. As it acts locally and does not create lingual anaesthesia or 'thick lip' there is no risk of the patient biting the lip and it is safe to use bilaterally on the mandible.

Using Quicksleeper S4 it is possible to anaesthetise between 2-8 teeth with just one injection - enabling more treatment to be performed per session.

Call 01380734990 or visit www. generalmedical.co.uk. 